\title{
The Future of Flexible Product Manufacturing by Using Industry 4.0 Technologies in Regard to Consumer Preferences
}

\author{
Muhammad Rahim Ejaz \\ University of Pecs
}

\section{THE AIMS OF THE PAPER}

The core objectives of this paper are to understand constantly changing consumer choices over time and the manufacturing of flexible products to answer the problem. The flexible products with multiple utility choices can help consumers from every segment to fulfil their needs. The study has shed light on the flexible product manufacturing process and has also discussed launching strategies into the market with having considered various market factors in the process.

\section{METHODOLOGY}

A rigorous analysis of literature has been done to understand why flexible products should be preferred over standard products. Literature related to flexible product strategy is being examined and explored its dimensions of price setting and product utility.

\section{MOST IMPORTANT RESULTS}

This study provides a road map for companies to shift their focus on developing new manufacturing processes in order to develop flexible products to address dynamic consumer preferences. This study also shed light on the fact the flexible products might be more profitable for the company.

\section{RECOMMENDATIONS}

The findings show that flexible products provide larger range of utility choices and with a right price; it can be more profitable than a standard product. Flexible products can go along with mass customisation of products which can enlarge utility choices for consumers to an unlimited level.

Keywords: Flexible Products, Industry 4.0, Mass Customisation and Consumer Preferences

DOI: 10.15170/MM.2021.55.03.01 


\section{INTRODUCTION}

It has been witnessed by Li et al. (2012) that there is a strong relationship between product design and consumer preferences. It is also a known fact that modular product designs gain more consumer attention than non-flexible product designs. This is a major reason why companies opt of modular product designs to gain maximal market share and to beat their competitors. Bonvoisin et al. (2016) define product modular design as "an activity of designing a product that is made up of modules" (Bonvoisin et al. 2016, 02). According to Li et al. (2012) now manufacturers have realized that the product designs preferred by the consumers are essential for firm's success and survivability in global competitive environment. Wei et al. (2017) also argue that a platform that allows product design flexibility is needed in order to reduce uncertainty, upgrade products and improve development cost and time. In order to do that they have adopted the strategy of quality function deployment (QFD) which enables the manufacturers to produce products according to the consumer preferences and it also covers the changing dimension of consumer preferences over time. Chan et al. (2002) define QFD as "an overall concept that provides the means of translating consumer requirements into appropriate technical requirements for each stage of product development and production" (Chan et al. 2002, 463). Saenz et al. (2018) argue that now market has been shifted to "on demand" based economy where consumer demand decides what to buy and manufacturer has to produce accordingly. According to Veryzer (1999) consumer preferences are behavioural responses based on their innate desires which can be influenced by their social environment, cultural and other factors. Tripsas (2008) argues that it is discontinuity in the consumer preferences that forces manufacturers to look for new technologies and manufacturing process in order to produce new flexible products.

In recent years' product designing have gained popularity in the manufacturing sector and now it is termed as a crucial part of product development. According to Boonman et al. (2015) flexibility is a competitive tool that can be used in markets filled with large number of flexible product manufacturers. According to Page et al. (2002) a study shows that $75 \%$ of respondents said that product design is the major reason of consumer attraction towards a particular product (Page et al. 2002, 133). Page et al. (2002) argue that there has been lots of literature available on the product design and its aesthetics but there is some literature available related to functionality of the product. Product functionality is an essential part of product design as in one example of VW beetle; it became popular in the consumer market because of its unique design and it stayed successful for a long time because of its functionality. Although there has been a lot of criticism on product design and functionality of the car but it remained popular car for decades.

Spence et al. (2011) state that consumers approach towards a certain product is based on their cognitive judgments and consumers make buying decisions about a particular product after having positive vibes from the product. This cognitive judgment may vary across consumers and products. Normally in consumer products; consumers fall for the aesthetic perspective of the product. On the other hand, some consumers fall for product quality which is not defined by the aesthetics of the product. For that purpose, usually consumers look for functionality perspective of the product. According to Page et al. (2002) functional characteristics of the product help consumers to evaluate and judge products on the basis of quality. Brand names also have a significant impact on the quality judgment by the consumers. A brand name like BMW brings a sense of quality and high functionality of a product so consumers may judge the product on a different criterion but on the other hand in the case of a low value brands; a consumer's cognitive judgement may differ in evaluating the products functionality. Vinokurova (2019) also argues that operations department can add or remove functional dimensions of flexibility in any given product and then marketing team creates demand for that particular product. In this way they make consumers adapt to the new product psychologically. They move consumers from one level of product utility to another.

This paper is focussed on the factors that are involved in the decision making process of flexible product development. Smith (2007) defines product development flexibility as "the ability to make changes as the product being developed or how it is being developed and without being disruptive". (Smith 2007, 2) Organisations need to be innovative and competitive while designing and launching flexible products into the market as competition can force the companies for continuous $R \& D$ to produce new products constantly keep up with the market forces.

Firms are usually not sure what might be the right strategy for product development because changes occur so often in the global business environment regarding consumer preferences. Organisations develop flexible products in terms 
of their functionality to reduce uncertainty to cater the wide range of consumer preferences. Products that can be used in multiple variations and can be reconfigured into different settings so that consumers can use them according to their need and desire are called flexible products. For example, electric shavers come with different trimmer sizes. This option gives consumers multiple choices to use the electric shaver. Nes et al. (2005) argue that flexible products last longer because they cannot be replaced by any other product so it might give companies a level of certainty in consumer market in terms of consumer preferences.

Based on the literature, these research questions are being formulated to answer the issues present in the literature. These issues are being explored in an extensive detail in this paper to sort out problems organisations face while dealing with dynamic consumer preferences, developing a flexible product manufacturing system and while launching new products into the markets.

RQ1: How a flexible product development strategy can affect consumer preferences?

RQ2: How organisations acquire a system for flexible product development?

RQ3: Why a new product launching strategy is critical for organisations?

Sections in this paper include flexible product development strategy; this section talks about why it is important for organisations to develop a flexible product strategy to cope with the incoming challenges. A rigorous review of the literature has been done to analyse pricing, utilization and customization of the flexible products to explore how organizations can strategize flexible product development, flexible product development system; this section explains the whole process that how an organisations initiates and finalizes a flexible product development process and flexible product launch strategies; this last section talks about the launching strategies of a new flexible product so that it can become a successful and profitable product.

\section{FLEXIBLE PRODUCT DEVEL- OPMENT STRATEGY}

Every company develops a strategy regarding new product development. It involves product features mainly like flexibility and standardisation in the products. Some companies opt for a standard product as it is aimed for producing one product for each and every consumer while on the other hand; some companies opt for flexibility feature as a pro- minent feature in their products to attract their consumers. Lafou et al. (2016) has defined flexibility as "the sensitivity of a system to change as more flexible the system; less sensitive to changes occurred in the environment" (Lafou et al. 2016, 99). Once a company decides to adopt flexible product strategy; they will embark on new product development process. According to Oliveira (2017) there are three major forms of flexibility; operational flexibility, product flexibility and capacity flexibility (Oliveira $2017,1326)$. Flexibility in product is defined by Schneider et al. (2020) as "the ability to adapt to change easily and reversibly whereas economically understandable easily and changeable back to the previous position rapidly" (Schneider et al. 2020, 814). Product flexibility is also defined by Suh et al. (2007) as the capability of a system to undertake specified changes of classes with ease (Suh et al. 2007, 68). The basic reason why companies go for products with flexibility feature is to capture all segments of consumers because with one standardised product a company cannot market all consumer segments. According to $\mathrm{Fu}$ et al. (2017) flexible products allows manufacturers to avoid potential mismatch for consumers.

Alptekinoğlu et al. (2019) argue that now consumers demand a single product with multiple variations; in short they expect a product to be flexible in terms of functionality so that larger consumer segment can take benefit from the product. For example, insulin pens with an option of adjustable insulin dosage. It can help consumers to adjust insulin according to their needs and also helps the company to capture larger market share and profits on the basis of flexibility attribute. In one other example in the case of medical devices like pacemakers and hearing aids, now companies have developed products like now a pacemaker can readjust itself according to the heart condition of the patient and similarly hearing aids now can adjust themselves according to their surroundings.

The motivation behind the idea of flexible product development is to answer variation and changing consumer demands over time. It also requires a technology to manufacture these kinds of products. A technology that can offer modularization in the product is an essential need to produce products with flexible features. Krajewski et al. (2013) have given a product process matrix that explains how different manufacturing processes can be adopted to manufacture products (Krajewski et al. 2013, 115). However, manufacturing process structure does not provide a lot of flexibility but it does provide mass customisation with low volumes which allows producing flexible products other than standard pro- 
ducts on the assembly lines or sub-assembly lines of the manufacturing system. Fritzsche et al. (2020) also argue that a certain level of flexibility is needed in the existing production line to develop a different variant of the product otherwise a new production line would be required to develop different variants of the existing product. Given the fact that consumers have been changing demands continuously and there is a variation in their preferences; companies usually opt for two kinds of strategies, 1. Standard product: in this strategy a company decides to offer multiple standardised products to capture major number of consumer segments. 2. Flexible product: in this strategy a company decides to offer a reconfigurable product which has variation in functionality so that major number of consumers can utilize the products to fulfil their needs.

Alptekinoğlu et al. (2019) state that they found that flexible products dominate standard products if they offer greater customer value through their developed theoretical model. They have also found an interesting relationship between product strategy and customer preferences in their study. Alptekinoğlu et al. (2019) argue that there are three possible consequences for companies when they produce flexible products. First, they have to reconsider the pricing of their product because from variety of standardised products now they are selling one flexible product. Secondly, now companies may have giving variety in their flexible product by offering them post purchase utility choices. Thirdly, companies may have empowering the consumers to do the reconfigure task of the product according to their changing needs. At this point the need of new product development arises which is flexible and reconfigurable to perform multiple tasks (Alptekinoğlu et al. 2019, 1560). This third approach leads to mass customisation. The three consequences described by Alptekinoğlu et al. (2019) are being explored in detail. It will help to understand why flexible products are becoming essential more than ever to fulfil consumer needs.

\section{Pricing of Flexible Products}

Revenue management is a science of pursuing long term profitability through better business decisions. Setting a price is very important as it lead towards revenue generation of an organisation. Pricing of flexible products is a new phenomenon and organisations need to sell at a differentiated price for maximum profits. According to Sierag (2016) flexible products can be sold at a lower price to inspire new consumer segments as flexible products lead to better utilisation and higher profits. Hence, numerical studies by Sierag (2016) shows that flexible products lead to $20 \%$ higher revenues (Sierag 2016, 337). Flexible products should be sold at a differentiated price because consumers are uncertain about the product utilisation and features but willing to buy. According to Rekettye et al. (2018) a perfect differentiated price would be a price which is higher and consumers are still willing to pay. It is known as price skimming strategy which is applied where consumer market segment is less price sensitive and cares about the value of the product (Rekettye et al. 2018, 155). It is also known as value segment. So, a differentiated price can be best suited to attract consumer segments which like multiple function products. Mang et al. (2011) state that the airline industry is the best example for flexible product pricing. An airline can offer a discount on a flexible ticket to make it more attractive for consumers than a standard ticket. Consumers who want to avoid uncertainty can be inclined towards flexible products at a discounted price. According to a research conducted by Mang et al. (2011) consumers are willing to pay for flexible products to avoid uncertainty. Moreover, the research shows that there is a positive relationship between consumer purchase and discounted price of the flexible products. Research also indicates that if product utility is high and can be availed for a longer period of time than there is a high probability of purchasing the flexible product by the consumers. The survey also indicates that flexible products at a discounted price bring $5 \%$ increase in the company's profits. Based on the research findings it can be argued that if a discount is given on a differentiated price of a flexible product then a flexible product can capture major share of consumer market.

\section{Flexible Products and Utility Choices}

According to Alptekinoğlu et al. (2019) standard products can cause misfit cost to the consumers which can result into failure in the product strategy. On the other hand, in case of flexible products, there is a reconfiguration cost; if that cost is higher than a consumer might not be inclined towards the product no matter how much the product is flexible. There is another interesting fact to note that flexible products are more likely to satisfy the changing consumer needs over time because flexible products are ideal products when there is uncertainty in terms of consumer preferences. Herpen et al. (2019) argue that organizations should produce products that offer utility that doesn't go beyond 
consumer needs. It will help to avoid product disutility. However, when consumer's preferences are not static and they tend to change over time; that means consumer's preferences are volatile which can lead to uncertainty. Nonetheless, standard products can also be profitable in the case of extremely low or high uncertainty in consumer preferences. It is also observed that flexible products are more suited for forward-looking consumers; the kind of consumers who favours innovation and novelty. Moreover, sometimes companies follow a hybrid product strategy where they offer both flexible and standard products in order to counter heterogeneity in consumer preferences. For example, Google App Engine, a cloud computing platform offers two different environments; one is standard and second is flexible. According to Alptekinoğlu et al. (2019) so far there are not a lot of studies that have been advocated the issues related to evolving consumer preferences and flexible products. Alptekinoğlu et al. (2019) suggest that in the new product development; technology plays a significant role. Especially the technologies that can help companies to enhance the ability to reconfigure and to redesign the flexibility of the products which is the chief concern here. For example, an improved programmable hearing aid that can be used electronically. It can be only possible with state of the art defect free manufacturing technologies.

\section{Flexible Products and Mass Customi- sation}

When companies are following mass customisation normally they use customised product strategy while on the other hand flexible products offer choice and variety beyond point of purchase and delays product differentiation. Alford et al. (2000) define mass customisation as "mass customisers develop, purchase, market and distribute goods and services with such verity that nearly everyone finds what exactly they want at the price which they can afford to pay" (Alford et al. 2000, 100). The concept of mass customisation supports consumer driven industrial system by developing business agility. Business agility can be developed through combining customisation and mass production. Rousseau et al. (2021) state that according to a survey market trends show that approx. $30 \%$ consumers have shown willingness to purchase customised products (Rousseau et al. 2021, 103). This research proves that three out of ten consumers are ready to customise their own product according to their needs and more consumers will follow this trend in near future. The most important finding of this study is that all the respondents are willing to pay for their customised products.

This trend provides an opportunity but this opportunity comes with the challenges. First, developing a configuration mechanism appropriate for consumers is a time consuming task which can result into complications on the manufacturer's end. Secondly, consumer preferences have very short lifecycle; they can change over time. So configuration system also needs to change when consumer preferences change. Sakao et al. (2017) argue that modularity in the manufacturing system is a key towards mass customisation. Modularity can help to minimize complications and ease the manufacturing process which would make mass customisation easy and faster for the consumers. Srinivasan et al. (2018) state that 3D printing can offer mass customisation rapidly to cater the short cycle time. Moreover, 3D printing can also solve the problem of manufacturing process flexibility as it has capability to produce mass customised products of any kind without consuming a lot of time on changing tooling equipment. Consequently $3 \mathrm{D}$ printing reduces the need of wide range of tools and equipment and also reduces the cost of manufacturing. With the help of 3D printing manufacturers can increase or decrease the production of customised products according to the need. Mass production might not be possible with $3 \mathrm{D}$ printing but manufacturing costs can be reduced. One of the most important prerequisite for mass customisation is consumer data. Manufacturers are relied on consumer data to analyse consumer preferences and changing trends over time. Technologies like Big Data can help organisations to develop a product customisation system backed by data that can help consumers to customise products according to their preferences. Rousseau et al. (2021) argue that an online product configurator is the solution to the mass customisation problem. Product configuration system is a knowledge based system that helps consumers to customise products according to their preferences with the available options.

\section{FLEXIBLE PRODUCT DEVEL- OPMENT SYSTEM}

An organisation requires flexible manufacturing system to produce flexible products at any given times. According to Palominos et al. (2019) a flexible product manufacturing system allows organisation to shorter product cycles and improved competitiveness. Flexible product development is 
important because it helps to deal with uncertainties however the decision making process to develop flexible manufacturing is rather inadequate. It requires proper understanding and knowledge so that it would be economically productive and competitive. Zhang et al. (2009) argue that now firms are focusing on developing flexible manufacturing abilities so that they answer the changing consumer preferences over time. The development of flexible manufacturing strategy is a challenging task due to many uncertainties. According to Wang et al. (2019) these uncertainties might be uncertain processing time, uncertain processing cost and uncertain machine breakdowns which can result into the failure of whole production scheduling process.

Product development flexibility is an attribute which allows manufactures to produce multiple products in order to minimize potential losses due to change in consumer preferences or due to technology disruption. It will not only help manufacturers to act quickly to respond change in consumer preferences but also helps them to innovate new product designs in the process. Moreover, this attribute will also help manufacturers to elevate their capabilities of producing new products and to improve their manufacturing processes as a whole. As it also argued by the Asadi et al. (2019) that variety of products will only add into complexities of the manufacturing process of a company. So there is a growing demand in the consumer market of flexible products and it will drive companies towards flexible product manufacturing systems. Flexible product manufacturing systems are manufacturing systems that are based on mixed-product assembly lines. Their assembly lines are flexible and they can be used to produce products with variations according to the fluctuations in the demand of product mix.

Zhang et al. (2009) raised two aspects related to new product development and its functional flexibility (Zhang et al. 2009, 144). These two aspects are product concept flexibility (CF) and product prototype flexibility (PF). CF is an early stage of product development and at this level firms explore and conceptualize several ideas for new products. The next phase of product development is producing product prototype. A product prototype is used for consumer feedback, engineering checks and product testing in order to ensure that when this product goes for mass manufacturing it is error free and grabs consumer attention. It is very important that both CF and PF work together to develop a product that can attain consumer preferences. As it is discussed earlier that flexibility in the product development is the only way to produce products with absolute certainty that these products will meet consumer satisfaction. CF and PF are very important dimensions in order to produce variety of product concepts and prototypes as working models to achieve the ultimate goal of producing a product which meets consumer satisfaction.

First dimension $\mathrm{CF}$ is an ability of a firm to generate product concepts that can satisfy consumer needs. In the process a firm can develop multiple product concepts and send them for product development so that a new product can be developed in minimum possible time. In the traditional way of product development companies develop products and then modifies them according to the consumer feedback and market analysis. It is a time consuming and costly process while on the other hand CF allows companies to work out their concepts through R\&D so that the goal of an error free product concept could be achieved. In the case of second dimension which is PF; it is an ability of a firm to produce physical models in less time as possible and most importantly with low cost. A prototype is like an artefact with having same attributes of products like functionality, quality and aesthetics. At this stage, a product designer can improve the functionality of the product to meet consumer satisfaction level. According to Zhang et al. (2009) prototypes are an excellent way of learning about unheard needs of consumers. It will help firms to adapt according to the rapid change in the consumer requirements. Many Japanese firms are using this strategy to responding change in consumer preferences in no time. At this stage several numbers of prototypes can be created and tested to develop a wider range of products.

Flexibility is an option which can have real positive impact on a new product development project. It is believed that literature does not fully reveal the significance of flexibility for a firm in the development of new product in a competitive market where the new product is going to be launched. Kettunen et al. (2015) suggest three segments in the new product development process. These three segments are initial development, additional development and market phase (Kettunen et al. 2015, 893). At the first stage of initial development; a firm develops a product for the purpose of launching it into the market. During the developmental process, performance, desirability and functionality of the product are assessed on a certain criterion. At this stage a firm can make decisions like to continue or abandon the product development, what will be the cost of the product, which features to be added or not and which technology to be used for the product development. After the completion of initial devel- 
opment stage, the firm begins with second stage which is additional development. At this stage a firm may go to the third stage without adding additional aspects to the products. It is more of a review stage where progress of first stage is analysed and firms make sure that if something is required to be removed or added or not. Normally there is no time limit at this stage but firms try to further as quickly as possible to the third stage. After the completion of second stage firms launch their products into the markets. The third and final stage is market phase where newly developed product is launched to be tested for market performance.

Figure 1. Flexible Product Development Process

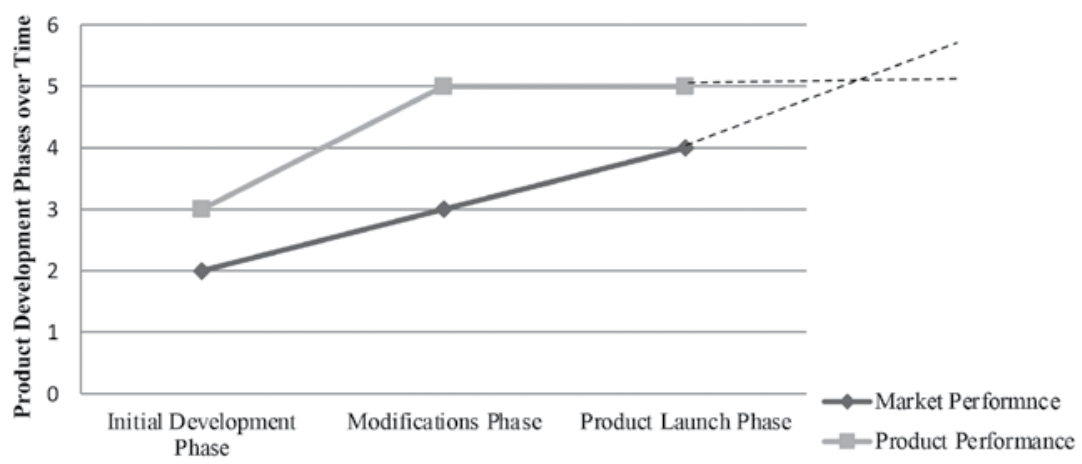

Source: Kettunen et al. 2015, 894

In the Figure 1 it can be seen that new product development is a two dimensional process. At first phase, a firm starts new product development with available resources and in the meanwhile market performance also grows in the time. At the second phase of the product development process, a firm decides to make amendments to the newly developed product if necessary. As the third phase approaches a firm launches its newly developed state of the art product which is superior to any other product available in the market. As graph shows that it remains superior for a time but as time passes; market evolves and competitors will launch products of their own surpassing your product. For example, Zara's success is credited to the ability of rapid modifications in their product offerings. According to Arnett et al. (2018) it is instrumental for companies to redesign their products and services as in response to the changing dynamics of the marketplace.

It can be observed that this new product development process is based on the idea of $\mathrm{CF}$ and $\mathrm{PF}$ dimensions of new product development which was floated by Zhang et al. (2009). CF can be denoted as initial development process and $\mathrm{PF}$ can be regarded as additional development process. According to Jiang et al. (2019) firms should adopt consumer centric approach towards new product development. Consumer surveys are the best source of getting preferences pre-hand. This information can help companies as they can incorporate this data in the development of new product. It is believed that there is a strong relation between consumer preferences and new product development. However, consumer preferences may change over time and there are certain limitations if we try to develop a model based on consumer preferences because it is hard to predict future consumer preferences and accuracy of the collected data would be also in question.

\section{FLEXIBLE PRODUCT LAUNCH STRATEGIES}

Some aspects like a firm's strategy regarding launch of the newly developed product can have a significant impact on the success of the product in terms of consumer satisfaction and profits. Wu et al. (2019) argues that swift changes in the technologies and in consumer preferences are causing companies to launch new products now and often. In this regard it is always been a critical decision for a com- 
pany to launch a new product in the market. The dilemmas that a firm normally faces are if a newly launched product fails to grab consumer attention or if a newly launched product is not as flexible in terms of functionality as compared to competitors or it is not up to the level of consumer satisfaction than the product is doomed. A firm must get right answers to these questions otherwise one wrong move can put a company out of business. Some companies follow watch and wait policy by delaying the launch of their newly developed product. In this policy companies allow their competitors to launch their product first in order to assess the consumer behaviour and market reaction towards the product. Sometimes it benefits and in some instances it resulted into decreased market share.

Firms also consider other uncertainties like forecasting of market threats, how much to invest, when to launch the new product and other related issues that arise during the time of new product development. These are kind of decisions that if a firm takes them on time then they can prove vital in the development of new product. Even big MNCs face such kind of dilemmas in the process of launching their new products in the markets. For example, Microsoft delayed the launch of Windows Vista in 2005 due to the threat of severe market competition; they feared that it will bring negative impact on the sales but it turns out that delaying the launch was a mistake and it brought negative impact on the profitability of Microsoft that year. In one other example Apple launched iPhone 4S due to market pressure because the launch of iPhone 5 was delayed and this decision turned out to have negative impact on the Apple brand.

In one example, Boeing delayed its B787 and waited for Airbus to launch its A380 in the market. This decision resulted into huge success as Boeing was able to secure three times more orders than Airbus because their product was more cost effective for airline carriers. In the aviation industry time is very essential so market players often adopt watch and wait policy but in consumer electronics industry where several companies are launching their new products in the market at a same time throughout the year. It requires a strategy and time management to respond to the market needs and consumer preferences rapidly as it is discussed earlier. Similarly, there is another strategy by the name of solo-roll policy which is adopted by numerous companies in the event of new product launch to avoid cannibalisation effect. According to Wu et al. (2019) in this case old products are replaced by new products and this strategy is common in many industries like fashion, IT, automobiles and in services. In one example Microsoft terminated the sales of Windows 7 and Windows 8 before the launch of Windows 10 in 2015. In one other example big fashion brands like Zara and H\&M also adopted the same strategy; they replace old products with new products every year. Some companies discontinue the supply of their products before the launch of their new products. In one example Canon discontinued its 7D Mark-II DSLR camera when their new 7D Mark-III DSLR was about to be launched in the market.

\section{CONCLUSION}

In this paper the formulation of strategies for flexible product development is the first research question which has been discussed in detail in the light of present literature. The extensive analysis of the literature tells that there are three basic pillars for the strategy of flexible products development. These pillars are pricing, utility choice and mass customisation. Every organisation which chooses to adopt the strategy to develop flexible product has to consider these pillars as basics for a strategy formulation. In pricing, organisations have to adopt a pricing strategy that attracts consumers but yet differs from the standard product's price. In utility choices, a product has to be flexible enough to provide different utility choices to the consumers; otherwise there is no point in developing a flexible product. In mass customisation, industry 4.0 technologies might play a crucial role in the mass production of mass customised products. Technologies like 3D printing and big data can help to achieve this goal.

As far as second research question is concerned, in flexible product development process organisations has to work on two basic things which are concept flexibility and prototype flexibility. A product concept should not be rigid in nature; it should be flexible. It is important so that it can be modified according to market and consumer needs. Similarly, prototype flexibility is also crucial for a flexible product development process. Its flexible nature will help organisations to remove unwanted features from the product and add desired features so that it could satisfy consumer needs better than its competitors. It is elaborated in the graph that market is always working on the development of new products and launching them when they are ready. A company's product maybe ahead of market competitors at the time of launch but this market leading position can be lost over time due to continuous product development. That is the reason why a product's concepts and prototypes should be flexible in nature. 
The third research question is about the launch strategies for a flexible product. According to the findings it can be concluded that there is no one standard way to find out a perfect launching strategy of a product for a company. Every organisation has to analyse their own market dynamics and decide when to launch their products. It can become risky for organisations because bad timing for product launch can hurt the sales and image of the product which can ruin the hard work done by the different departments of an organisation.

The paper tries to answer three raised questions by analyses of the scientific literature. There is lot more in this field that has to be done and this paper has provided a knowledge with a limited scope that how and why consumer preferences are changing towards flexible products and how organisations answer to this rising challenge with the help of Industry 4.0 and continuous product development so that it could stay up to date with other competitors in the market.

\section{REFERENCES}

Alford, D., Sackett, P. \& Nelder, G. (2000), "Mass customisation - an automotive perspective", International Journal of Production Economics, 65(1), 99-110. DOI: 10.1016/S09255273(99)00093-6

Arnett, D., Sandvik, I. \& Sandvik, K. (2018), “Two paths to organizational effectiveness - Product advantage and life-cycle flexibility", Journal of Business Research, 84, 285-292. DOI: 10.1016/j.jbusres.2017.11.010

Alptekinoğlu, A. \& Ramachandran, K. (2019), "Flexible Products for Dynamic Preferences", Production and Operations Management, 28(6), 1558-1576. DOI: 10.1111/ poms. 12990

Asadi, N., Jackson, M. \& Fundin, A. (2019), "Implications of realizing mix flexibility in assembly systems for product modularity - A case study", Journal of Manufacturing Systems, 52, 13-22. DOI: 10.1016/j.jmsy.2019.04.010

Bonvoisin, J., Halstenberg, F., Buchert, T. \& Stark, R. (2016), "A systematic literature review on modular product design", Journal of Engineering Design, 27(7), 488-514. DOI: $10.1080 / 09544828.2016 .1166482$

Boonman, H., Hagspiel, V., \& Kort, P. (2015), "Dedicated vs product flexible production technology: Strategic capacity investment choice", European Journal of Operational Research, 244(1), 141-152. DOI: 10.1016/j. ejor.2015.01.007

Chan, L. \& Wu, M. (2002), "Quality function deployment: A literature review", European Journal of Operational Research, 143(3), 463497. DOI: 10.1016/S0377-2217(02)00178-9

Fritzsche, R., Voigt, E., Schaffrath, R., Todtermuschke, M. \& Rober, M. (2020), "Automated design of product-flexible car body fixtures with software supported part alignment using particle swarm optimization", Procedia CIRP, 88, 157-162. DOI: 10.1016/j.procir.2020.05.028

Fu, Q., Wang, Q., Xu, X., \& Lian, Z. (2017), “A two-product newsvendor system with a flexible product", International Journal of Production Economics, 193, 590-601. DOI: 10.1016/j. ijpe.2017.08.018

Herpen, E., \& de Hooge, I. (2019), "When product attitudes go to waste: Wasting products with remaining utility decreases consumers' product attitudes", Journal of Cleaner Production, 210, 410-418. DOI: 10.1016/j.jclepro.2018.10.331 
Jiang, H., Kwong, C., Okudan Kremer, G. \& Park, W. (2019), "Dynamic modelling of customer preferences for product design using DENFIS and opinion mining", Advanced Engineering Informatics, 42, 100969. DOI: $10.1016 / \mathrm{j}$ aei.2019.100969

Kettunen, J., Grushka-Cockayne, Y., Degraeve, Z. \& De Reyck, B. (2015), "New product development flexibility in a competitive environment", European Journal of Operational Research, 244(3), 892-904. DOI: 10.1016/j. ejor.2015.02.016

Krajewski, L., Ritzman, L. and Malhotra, M. (2013), Operations Management. 10th ed. Boston: Pearson, 114-116.

Lafou, M., Mathieu, L., Pois, S. \& Alochet, M (2016), "Manufacturing System Flexibility: Product Flexibility Assessment", Procedia CIRP, 41, 99-104. DOI: 10.1016/j.procir.2015.12.046

Li, Y., Tang, J., Chin, K., Luo, X., Pu, Y. \& Jiang, Y. (2012), "On integrating multiple type preferences into competitive analyses of customer requirements in product planning", International Journal of Production Economics, 139(1), 168-179. DOI: 10.1016/j.ijpe.2012.03.031

Mang, S., Post, D., \& Spann, M. (2011), "Pricing of flexible products", Review of Managerial Science, 6(4), 361-374. DOI: 10.1007/s11846011-0075-4

Nes, N. V. \& Cramer, J. (2005), "Influencing product lifetime through product design", Business Strategy and the Environment, 14(5), 286-299. DOI: $10.1002 /$ bse.491

Oliveira, S. (2017), "High Radicality of Product Innovation and High Flexibility and High Agility of System of Manufacturing: Towards the Smart Factories", Procedia Manufacturing, 11, 13241334. DOI: 10.1016/j.promfg.2017.07.261

Page, C. \& Herr, P. (2002), “An Investigation of the Processes by Which Product Design and Brand Strength Interact to Determine Initial Affect and Quality Judgments", Journal of Consumer Psychology, 12(2), 133-147. DOI: $10.1207 / 153276602760078668$

Palominos, P., Quezada, L., Donoso, J. \& Gonzalez, M. (2019), "A Model of Economic Evaluation for the Acquisition of Flexible Manufacturing Technologies", Procedia Manufacturing, 39, 565-573. DOI: 10.1016/j.promfg.2020.01.420

Rekettye, G., \& Liu, J. (2018), Pricing The New Frontier (1st ed.). London: Transnational Press London.

Rousseau, M., Medini, K., Romero, D. \& Wuest, T. (2021), "Configurators as a means to Lev- erage Customer-Centric Sustainable Systems - Evidence from the 3D-Printing Domain", Procedia CIRP, 96, 103-108. DOI: 10.1016/j.procir.2021.01.060

Sáenz, M., Knoppen, D. \& Tachizawa, E. (2018), "Building manufacturing flexibility with strategic suppliers and contingent effect of product dynamism on customer satisfaction", Journal of Purchasing and Supply Management, 24, 238246. DOI: 10.1016/j.pursup.2017.07.002

Sakao, T., Song, W., \& Matschewsky, J. (2017), "Creating service modules for customising product/service systems by extending DSM", CIRP Annals, 66(1), 21-24. DOI: 10.1016/j.cirp.2017.04.107

Schneider, D., Fröhlich, T., Huth, T. \& Vietor, T. (2020), "Design for Flexibility - Evaluation Interactions between Product Properties and Production Processes", Procedia CIRP, 91, 814-818. DOI: 10.1016/j.procir.2020.02.240

Sierag, D. (2016), "Pricing-based revenue management for flexible products on a network", Journal of Revenue and Pricing Management, 16(3), 325-339. DOI: 10.1057/s41272-016-0061-1

Spence, C. \& Gallace, A. (2011), "Multisensory design: Reaching out to touch the consumer", Psychology and Marketing, 28(3), 267-308. DOI: 10.1002/mar.20392

Smith, P. (2007), Flexible Product Development: Building Agility for Changing Markets. (1st ed.) San Francisco: John Wiley \& Sons/Jossey-Bass. Srinivasan, R., Giannikas, V., McFarlane, D., \& Thorne, A. (2018), "Customising with 3D printing: The role of intelligent control", Computers In Industry, 103, 38-46. DOI: 10.1016/j. compind.2018.09.003

Suh, E., de Weck, O., \& Chang, D. (2007), "Flexible product platforms: framework and case study", Research In Engineering Design, 18(2), 67-89. DOI: 10.1007/s00163-007-0032-z

Tripsas, M. (2008), "Customer preference discontinuities: a trigger for radical technological change", Managerial and Decision Economics, 29(2-3), 79-97. DOI: 10.1002/mde.1389

Veryzer, R. (1999), "A nonconscious processing explanation of consumer response to product design", Psychology and Marketing, 16(6), 497-522. DOI: 10.1002/ (SICI)1520-6793(199909)16:6<497: AIDMAR4 $>3.0 . C O ; 2-Z$

Vinokurova, N. (2019), "Reshaping demand landscapes: How firms change customer preferences to better fit their products", Strategic Management Journal, 40(13), 2107-2137. DOI: 10.1002/smj.3074 
Wang, Z., Pang, C. \& Ng, T. (2019), "Robust scheduling optimization for flexible manufacturing systems with replenishment under uncertain machine failure disruptions", Control Engineering Practice, 92, 104094. DOI: 10.1016/j. conengprac.2019.07.012

Wei, W., Ji, J., Wuest, T. \& Tao, F. (2017), "Product Family Flexible Design Method based on Dynamic Requirements Uncertainty Analysis", Procedia CIRP, (60), 332-337. DOI: 10.1016/j. procir.2017.01.037

Wu, C. \& Lai, J. (2019), "Dynamic pricing and competitive time-to-market strategy of new product launch under a multistage duopoly", European
Journal of Operational Research, 277(1), 138152. DOI: 10.1016/j.ejor.2019.02.012

Zhang, Q., Vonderembse, M. \& Cao, M. (2009), "Product concept and prototype flexibility in manufacturing: Implications for customer satisfaction", European Journal of Operational Research, 194(1), 143-154. DOI: 10.1016/j. ejor.2007.12.013

Muhammad Rahim Ejaz, PhD candidate rahim.ejaz@live.com University of Pecs Faculty of Business and Economics 